\title{
An Unusual Case of Incisional Hernia
}

\author{
Lt Col D Chopra,vsm*, Lt Col A K Pandey (Retd) ${ }^{+}$, Late Lt Col D N Misra ${ }^{\#}$, Lt Col J N Lakhe**, \\ Lt Col R Kakkar (Retd) ${ }^{++}$, Col K R Salgotra ${ }^{\# \#, ~ B r i g ~ S ~ K ~ M a u l i k ~(R e t d) ~}{ }^{* * * *}$
}

MJAFI 2005; $61: 275-276$

Key Words: Incisional hernia; Lower segment; caesarian section; Pedunculated fibroid uterus; Polytetrafluroethylene

\section{Introduction}

$\mathrm{A}$ $\mathrm{n}$ incisional hernia is one that develops in the scar of a surgical incision. There is a risk of strangulation with a narrow neck and large sac. Thin walled hernias may ulcerate and develop intestinal fistula. The longterm incidence in best centers is $10 \%$. Predisposing factors are obesity, age, wound infection and incisions more than $18 \mathrm{cms}$. Common contents are omentum, transverse colon, loops of small bowel and stomach [1]. Although gravid uterus in an incisionsal hernia has been reported earlier[2], the occurrence of incisional hernia 25 years after laparotomy with a pedunculated fibroid uterus as its content is extremely rare (Fig 1).

\section{Case Report}

Fifty six year old mother of a serving soldier presented with pain and swelling of lower abdomen since six years, increasing in size in last six months. She was also an old case of bronchial asthma over previous ten years and had last child birth in 1970 with twins delivered by Lower Segment Caesarian Section (LSCS). After LSCS she was asymptomatic till 1996 when she noticed a small lump which remained static for six years and started increasing in size over the previous six months. On examination her general condition was good, vitals normal, lungs clear, abdomen soft, swelling in lower abdomen more to right of mid-line, size $20 \times 15 \mathrm{~cm}$, not completely reducible, transillumination negative and cough impulse present. A $3 \times 2 \mathrm{~cm}$ gap was felt in linea alba in infra umbilical region on asking the patient to raise her leg or neck in supine position without support of arms. She was diagnosed as a case of irreducible incisional hernia with omentum as its content.

Under spinal anaesthesia converted to general anaesthesia, through an infra umbilical incision the sac was defined, opened, uterus was found lying outside the sac with a kidney shaped $12 \times 8 \mathrm{~cm}$ fleshy growth attached to it. Adhesions with parietal peritoneum were released. Bladder was catheterized, dissected free from uterus, planes defined and subtotal hysterectomy with bilateral salpingo-oophrectomy was done. Extra margins of sac with extra-peritoned fat were excised. Rectus shealth and linea alba on each side were dissected and resutured using 1/o prolene with reconstruction of linea alba in two layers. Wound was closed leaving a parietal and pelvic drain.

Post operatively the patient made an uneventful recovery. She was discharged on the $13^{\text {th }}$ post op day and has been followed up for 6 months with no recurrence.

\section{Discussion}

Incisional hernia is one that develops in the scar of a surgical incision. Most incisional hernias (66\%) develop within 5 years. Remaining (33\%) develop in next 5-10 years [3]. The occurrence of a incisional hernia after 26 years of LSCS is rare. The presence of uterus with a Leimyoma attached to it is extremely rare. Recently a case involving the urinary bladder has been reported [4]. The causative factor in this case is age and associated bronchial asthma as a pre-disposing factor. The ageing and weakening of tissues and the raised intra-abdominal pressure associated with chronic cough, constipation and prostation are cited as factors. Pre-operative management included reduction of weight and control of asthma. Anti-microbal prophylaxis with inj Cefatoxime was given to obviate infection due to prolonged tissue handling. Operative method used in this case was fascial repair resuture technique as adequate margins of the linea alba were available. Other methods include shoelace repair [5], synthetic non absorbable prolene mesh closure [6] and laparoscopic mesh repair [7]. Histopathological examination of the specimen showed leimyoma (fibroid) uterus. Cut section of the kidney shaped mass showed white fleshy tissue and microscopic examination of the specimen showed spindle shaped cells arranged in whorls consistent with fibroid uterus. There are many aetiologicl factors responsible for incisional 


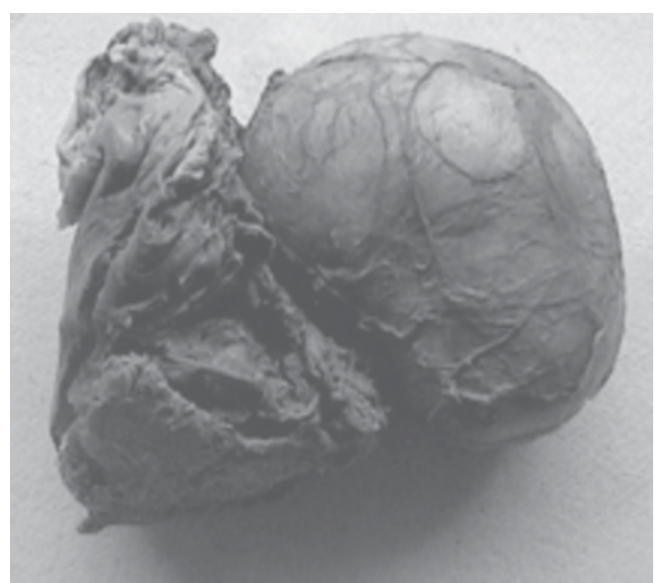

Fig. 1 : Incisional hernia (optd) - uterus (left), tumour (right)

hernia. When more than one factor coexist in the same patient, the likelihood of post operative wound failure is greatly increased. The factors pre-disposing to incisional hernia include poor surgical technique, post operative wound infection, old age, general debility, obesity, post operative pulmonary complications, placement of drains or stomas in the primary operative wound, intraoperative blood loss greater than $1000 \mathrm{ml}$, failure to close the fascia of laparoscopic trocar sites over $10 \mathrm{~mm}$ in size, etc.

A hernia is considered to be large when the fascial edges cannot be approximated without tension. In repair of hernias, spinal or epidural anaesthesia gives superior relaxation, though general anaesthesia with the addition of muscle relaxants also works well. In performing the repair, excess scarred skin and sub-cutaneous tissue over the hernia are removed. The hernia sac is than carefully dissected free from underlying muscles and fascial tissues. If there is incarceration or adhesion of intra-peritoneal contents, the abdominal contents should be dissected free from the sac and dropped back into the abdomen. The edges of the fascial defect should be cleaned so that the closure will be to solid fascial tissue rather than the scar.

Primary closure of a large defect is not advisable since tension on closure increases the risk of hernia recurrence. Increasingly repair of large or recurrent defects is performed using non-absorbable mesh eg., Prolene or polytetrafluroethylene (PTFE) mesh. Although a variety of techniques exist for placement of the mesh, a retrorectus inlay or sandwich technique achieves a lower recurrence rate than an edge-to-edge or onlay placement. If a large dead space persists, a closed drainage system is usually employed in the space above the fascia. A primary fascial closure should be used only if the fascia can be brought together without tension.

Laparoscopic techniques are also currently being used to repair incisional hernia and perform adhesiolysis electively. A synthetic material, usually PTFE is secured to the abdominal wall as in inlay graft. The intraperitoneal placement of the graft enhances the durability of the repair, though it also increases the risk of bowel adhesions or fistula formation.

The recurrence rate for first time incisional hernia repairs varies directly with the size of the fascial defect. Small hernias have a recurrence rate of $2-5 \%$, medium sized hernias recur in 5-15\% of cases and large hernias closed under tension, have a recurrence rate approaching $50 \%$. Repair of recurrent incisional hernias is even less likely to succeed, with a recurrence rate exceeding $50 \%$ [8].

The occurrence of an incisional hernia more than 25 years after LSCS with uterus and a pedunculated leiomyoma as its content is extremely rare and not reported.

\section{References}

1. Abrahamson J. Hernias in Micheal J Zinner, Seymour I. Schwartz, Harold Ellis, editors. In Maingot's, Abdominal Operations Vol I, 10 ${ }^{\text {th }}$ ed. Appleton and Lounge, 1997,548-72.

2. Banerjee N, Deka D, Sinha A. Gravid uterus in an incisional hernia. Gynaecol Res $2001 ; 27(2): 77-9$.

3. Stoppa R. Hernia of the abdominal wall. In: Chevrel JP(ed). Surgery of the abdominal wall. Berline, Germany: SpringerVerlag 1987:55-60.

4. Boughey JC, Nottingham JM. Massive incisional hernia of the bowel and urinary bladder: a case report. Am Surg 2002 ;68(10):892-4.

5. Abrahamason J, Elder S. 'Shoelace' repair of large post operative ventral abdominal hernias: a simple extra pertitoneal technique. Contemp Surg 1988;33:24-30.

6. Bendavid R. The rational use of mesh in hernias. A prospective Int Surg 1992;77:229-300.

7. Cassar K, Munro A. Surgical treatment of incisional hernia. $\mathrm{Br}$ J Surg $2002 ; 89(5): 534-45$.

8. Karen E.Deveney, Hernias and other Lesions of the Abdominal wall In Lawerence W.Way, Gerard M. Dohesty editors In: Current surgical diagnosis and treatment, $11^{\text {th }}$ edition Lange/ McGraw Hill 2003,792-3. 